\title{
Bray, M. (2009). Confronting the Shadow Education System: What Government Policies for What Private Tutoring? Paris: International Institute for Educational Planning. 134 p., ISBN 978-92-803-1333-8.
}

Reviewed by Katarina AšKerc ${ }^{\star 1}$ And Romina PlešEc Gasparič²

In this publication, Mark Bray, the director of UNESCO's International Institute for Educational Planning (IIEP) between 2006 and 2010, introduces private supplementary tutoring, a phenomenon that several countries have been facing in different forms and with different intensity for quite some time. Private supplementary tutoring represents the "shadow" of the formal education system, since changes in the education system also change private supplementary tutoring, which would not even exist without the former. Being familiar with the shadow enables the observer to identify changes taking place within the system and its broader context. With the meaningful title, the author also exposes the dilemma that policymakers and planners face in dealing with and responding to this phenomenon and its growth, which demands constant observation and analysis, since different circumstances require different responses and measures. The author supports his observations with explicit and exact analyses and descriptions of the situation and changes in different countries. Moreover, he uses many illustrative real-life examples and student ${ }^{3}$ experiences, which add to the authenticity and clarity of the text. The publication is based on a UNESCO IIEP forum that was held under the same title in Paris in 2007 , and is a continuation of a study from $1999 .{ }^{4}$ The content refers only to fee-paying private supplementary tutoring of basic (i.e., academic) subjects at the primary and secondary levels of national education systems.

Despite many criticisms of private tutoring, there are certainly some positive effects, such as increased focus on the individual and consideration of their specific learning characteristics and needs, more interesting teaching, faster feedback, better student progress, etc., which should also be qualities of the formal education system. Students who are low achievers can benefit from private tutoring by catching up with what they have missed, while high achievers can attempt to attain even higher academic goals. However, the author is

$1 \quad{ }^{\star}$ Corresponding author. Slovenian Quality Assurance Agency for Higher Education katarina.askerc@gmail.com

2 Faculty of Education, University of Ljubljana and Primary School Vrhovci

3 The word 'student' is used for primary and secondary level students.

4 The shadow education system: private tutoring and its implications for planners. 
critical of private tutoring causing and enhancing social and economic inequality, dominating children's lives and reducing their free time. Furthermore, it can even distort the formal education curriculum, resulting in private tutoring shifting from being a passive shadow to having an active effect on the education system, either supporting or undermining it. It is important that policymakers and planners identify the phenomenon of private tutoring in time, realise the capacity of its (negative) effects and confront them.

In the first part of the present book, the author presents the extent, forms and patterns of private tutoring, as well as providing an overview of various countries and regions. Private tutoring can be carried out in a one-on-one setting with direct contact between the student and the private tutor, or in the form of lectures to a larger group of students. It can be organised on the basis of an individual agreement or within a private tutoring centre. With the development of technology, private tutoring is also provided with the help of modern ICT tools. The intensity and frequency of tutoring sessions vary according to (examination) periods, but it is found in countries with low and high revenues and in households with different incomes. Private tutoring is more frequent in urban than rural environments, and in some countries it is received by more boys than girls, ${ }^{5}$ etc. There are some extreme practices that catch the eye, e.g., the occurrence of corruption in some countries as the result of school teachers providing (or being forced to provide) private tutoring sessions. This often has negative consequences, as during regular instruction teachers omit parts of the curriculum knowing that students will receive tutoring lessons, sometimes even doing so in order to broaden the "market" for private tutoring. The author draws attention to the fact that different models of private tutoring demand different government policies: the market-driven form usually used by students with high learning results (e.g., in Korea and Japan) requires a different approach than government initiatives to introduce sponsored tutoring for students with poor learning results (e.g., in Australia and the USA). Tutoring of students that teachers teach in regular instruction (e.g., Mauritius) is different from finding a private tutor on the student's own initiative (e.g., in Singapore, teachers are forbidden to give private tutoring sessions to students they teach in regular instruction). Online tutoring is different from direct personal contact. Tutoring sessions provided by qualified professionals, i.e., professional teachers (active or retired), face-to-face or within a commercial company, differ from tutoring sessions provided by pedagogically unqualified high school students or university students.

5 In Egypt, where secondary schools are gender-segregated, private lessons provide an opportunity for students to meet peers of the other sex. 
Although there has always been a certain degree of private tutoring and there always will be, the author thinks it is problematic and alarming that nowadays this sector is becoming increasingly structured and commercialised. Two subchapters deal with the supply and demand of tutoring, supported by many examples and data from different countries, which the author uses to form answers to questions regarding the reasons for the (growing) occurrence of private tutoring. Private tutoring is a business in some countries: centres and companies on a local and multinational levels offer and charge for tutoring lessons. These can be a major expense for households or families looking for a way for their children to achieve high academic results and gain better social and economic opportunities in the future. It is therefore important to be aware of the fact that, with the rich investing in private tutoring, the poor are forced to follow suit, which causes great social and economic pressure on weaker families. The frequency and intensity of the phenomenon are largely dependent on cultural and social characteristics, which, at the same time, helps to explain the different private tutoring forms in various countries and regions. ${ }^{6}$

The forms of private tutoring are presented in three case studies with an exact and analytical approach, providing tables, citing documents, stating individual experiences and placing the situations into a broader context. The Korean education system ${ }^{7}$ follows the tradition of Confucianism, in which formal learning plays an important social role and the competitive spirit in education is deeply rooted in the nation. Private institutions with fee-paying evening and weekend classes have emerged to assist successful selection admission to higher levels of education. Private tutoring has resulted in high achievers ceasing to participate actively in classes, instead doing homework for private institution or even falling asleep during class. Academic success, and consequently private tutoring, is the main instrument of economic and social development, and even though numerous government directives and reforms have tried (quite ineffectively) to abolish such approaches, private tutoring is growing exponentially. The government in Mauritius has also tried several times to solve the problematic issues of private tutoring, which expands mostly towards the end of primary schooling, but with limited success. The education system is very selective

6 While Australia, England, France, Singapore and the USA have been looking for ways to stimulate demand for private tutoring, elsewhere the main intention has been to decrease or even prohibit demand for private tutoring: e.g., Korea, Mauritius, Cambodia, Egypt, Kenya, Turkey and Uganda. Some countries regulate private tutoring with state regulations (e.g., Lithuania, with the most structured system, as well as Kazakhstan, Mongolia, Slovakia, Tadzhikistan, Ukraine, etc.), while several countries do not have special regulations or have regulations that are ambiguous and unclear.

7 The total household expense for private tutoring in Korea in 2006 was as much as $2.8 \%$ of gross domestic product. 
and competitive and the curriculum is overfilled. Most private tutoring has to be carried out by regular teachers in school buildings, which causes additional pressure for students to attend. Surprisingly, data shows that by providing private tutoring lessons, primary level teachers in Mauritius can double or even triple their income. In France, where families that invest in private tutoring get certain tax allowances, private tutoring is a consequence not only of social and economic forces but also of a government initiative trying to increase the level of academic results. The present publication thoroughly presents case studies that include the introduction of sociopolitical facts. However, in some parts the text could be supported by a rough outline of the general national education system, which would help the reader unfamiliar with the specifics of each system to more clearly and profoundly understand the circumstances presented.

Reading about the interesting practices and the expansion of private tutoring, the reader wonders what policymakers and planners could and should do in order to confront the education system in the shadow. The author states that due to the lack of data they are often forced to use raw figures and estimates regarding private tutoring. The presented patterns, factors, causes and effects of private tutoring, placed in different contexts, certainly represent an important source of data and a good example of collecting and presenting data. Surely, more attention should be paid to adequate and effective data collection in different situations, such as in the aforementioned case studies, while presentation of data should be upgraded with successful further policymaking and implementation. Suitable and critical evaluation approaches are needed for determining policy effects. Certainly, it is important for policies to focus on the causes and not only the symptoms, thus not only the national specifics of education systems but also the social and economic dimensions (these three aspects are debated in a special subchapter) and international comparisons should be taken into account.

This leads to a question regarding the situation of the Slovenian education system. There are no special laws regulating private tutoring, nor are there taxes connected with it or prohibitions placed on it. We therefore trust the ethical principles of Slovenian teachers. Although we do not have any empirical research on private tutoring at hand, we assume that in Slovenia private tutoring does not achieve the extent presented in the present study. However, we can find advertisements of organisations and individuals offering and marketing private tutoring at all levels of education, especially for turning-point external examinations at the admission to a higher level of education. This raises several questions: what are the economic dimensions of private tutoring in Slovenia, what are the cultural and educational effects, and, above all, what are the social 
and direct financial consequences for students and their families? These are all important questions that demand answers. It is interesting that international research (e.g., TIMSS and PISA) shows that Slovenian primary and secondary level students have difficulties achieving certain competences, and this indirectly leads to the question as to whether there is a correlation between achieving these competences and receiving private tutoring (in different countries). In a short chapter, the author introduces international studies and rankings (TIMSS, SACMEQ, OSI and PISA) ${ }^{8}$ that, despite the difficulty of data collection, have contributed significant information on the shadow of the education system, while the PISA team has also discussed the collection of more specific data on private tutoring in future research.

Private tutoring has become a global phenomenon with different characteristics in different countries. Despite sometimes being introduced with well-intentioned government initiatives for low achievers, and despite having numerous positive effects, it is necessary to monitor private tutoring carefully. We agree with the author that policymakers and planners need to confront the education system in the shadow in order to identify appropriate answers and proactive measures for "visible" national education systems as well.

The present study is of interest to a wide circle of readers; it is certainly useful for policymakers and planners, educators and educators of educators. By presenting a number of good and bad practices throughout the world, it is a significant aid to identifying forms of private tutoring and planning suitable measures. Raising awareness about the phenomenon of private tutoring, its scope, expansion and influence, is undeniably important for educators, since opening these kinds of questions leads them to professional consideration of the quality of pedagogical work in national education systems, and to a critical search for opportunities to improve it.

8 TIMSS (Third International Mathematics and Science Study and its successor Trends in International Mathematics and Science Study, 1995, 1999, 2003), SACMEQ (Southern and Eastern Africa Consortium for Monitoring Educational Quality, 1995, 2000, 2007), OSI (Open Society Institute, 2004-2005, 2005-2006, 2007), PISA (Programme for International Student Assessment). 